УДК 621.436

А.Д. Коровянская, В.В. Лебедев

\section{УЛЬТРАЗВУКОВАЯ ФОРСУНКА}

Предложен новый тип форсунки, в которой энергия подводится не к жидкости и газу, а к самой конструкции. Ультразвуковой принцип распыления на основе явления магнитострикции позволяет обеспечить стыковку форсунки с системой электронного управления впрыском топлива.

Ключевые слова: ультразвуковая форсунка, распыление топлива, тепловой двигатель, ультразвуковой распылитель.

\section{A.D. Korovyanskaya, V.V. Lebedev}

\section{ACOUSTIC BURNER}

More full fuel atomization increases the combustion efficiency, coefficient of performance, reduces pollution emissions. The purpose of the article is to investigate the possibility of ultrasound application for fuel automation in heat engines.

In the article a new type of burner is presented. The energy there is supplied not to the liquid and gas, but to the structure itself. The ultrasonic principle of diffusion based on magnetoelastic effect lets the jointing of the burner with the system of electronic control of fuel atomization. The calculations showed, that energy costs are manifold less than heat engine power supply. Ultrasound fuel atomizer can be used with any kinds of heat engines, which are operating on liquid fuel.

Key words: acoustic burner, fuel atomization, heat engine, ultrasonic atomizer.

Первоначально цель работы заключалась в изготовлении школьной лабораторной установки для демонстрационных опытов с ультразвуком. Но после первых удачных опытов определилось важное практическое направление установки для распыления топлива в тепловых нагревателях и двигателях различного типа. Более полное распыление топлива увеличивает полноту сгорания, повышает коэффициент полезного действия, уменьшает количество вредных выбросов. Эти факторы повышают энергоэффективность, ресурсосбережение тепловых двигателей, улучшают экологическую ситуацию при их работе.

В школьном кружке случайно была найдена книга [1], в которой рассказано, как сделать простую установку для получения ультразвука. Надо изготовить магнитострикционный излучатель из ферритового стержня, соленоида и постоянного магнита. В кабинете физики есть школьный генератор сигналов низкой частоты ГЗШ, к нему можно подключать излучатель и проводить опыты с ультразвуком. Такую установку сделали. Она работает лучше, чем генератор ГЗШ. Во время работы сразу же появилось много вопросов, в т.ч. по современной элементной базе. В кабинете физики нашли две коробки транзисторов КТ803А, они обратной проводимости, а характеристики приблизительно те же, только рабочая частота больше. Схема с такими транзисторами приведена в [2]. Однако схема была собрана раньше обращения к литературному источнику, поэтому имеет ряд отличий, хотя и не может претендовать на приоритет. Подключили на вход нового мощного транзистора маломощный звуковой генератор Г3-36 и добились коллекторного тока до 4А. Мощность излучателя оказалась такой, что ферритовый стержень сразу сломался. Уменьшили мощность и стали решать следующую задачу: все время носить с собой даже маленький генератор ГЗ-36 нельзя, не говоря о тяжелом генераторе ГЗШ, нужен отдельный задающий генератор.

В школе информатику изучают как программирование без элементной базы. Старая микросхема К155ЛА3 позволила внедрить информатику в ультразвуковой генератор. Цифровые схемы настраивать не надо, они сразу выдают информационный сигнал в виде логических нулей и единиц. Мультивибратор с микросхемой заработал с первого раза, но цифровой сигнал был настолько слаб, что не получилось открыть мощный транзистор КТ803А. Был найден транзистор КТ904, который хорошо открывался цифровым сигналом микросхемы. Этот транзистор поставили в первый каскад усилителя, сигнал с него подали на второй каскад с мощным транзистором.

Очередная задача - электропитание схемы. Решение нашли в микросхеме КРЕН5В или зарубежном аналоге 7805. Все транзисторы и микросхемы надо охла- 
ждать. С этим проблем нет, если устройство разместить в корпусе компьютерного блока питания. Вентилятор в нем работает, а все остальное надо убрать. Три реостата позволяют точно подобрать частоту резонанса. Если на входе установить диод, то схему можно питать переменным током, но емкости фильтрующих конденсаторов малы для сглаживания пульсаций даже двухполупериодного выпрямителя. Удобно сделать отдельный трансформатор с выпрямителем на 12 В, чтобы питание было универсальным. Диод желательно заменить диодным мостом с емкостным фильтром для сглаживания пульсаций. В [2] задающий генератор предлагается собирать на микросхеме-таймере NE555. Изготовленный генератор испытан, работает надежно [5]. Схема двухкаскадного усилителя сигнала приведена на рис. 1.

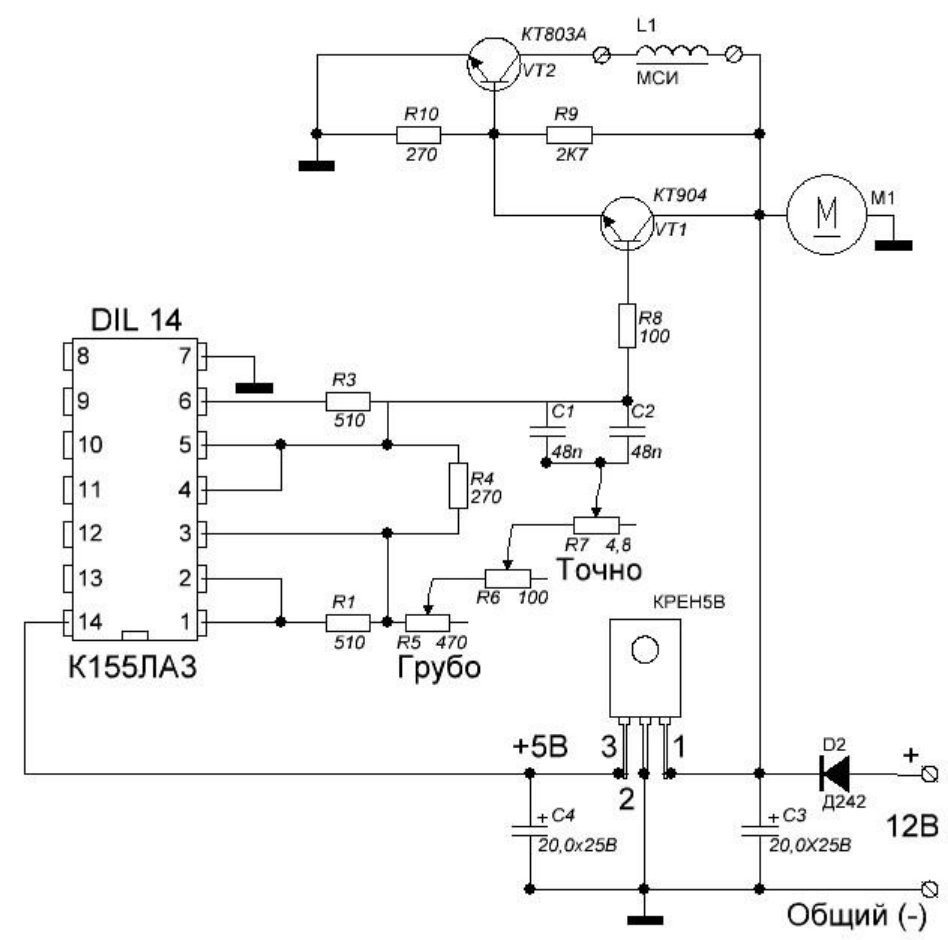

Рис. 1. Принципиальная схема генератора сигналов с частотой $5 \ldots 20$ кГц

Следующая задача - изготовить ламповый генератор. Уже начаты работы [3] с пентодом ГУ-81М, но пока рекомендовано их отложить из-за анодного напряжения $6 \ldots 7$ кВ. Нецелесообразно повторять известную [1] и устаревшую схему на лампах 6П6С, в планах применить две самые надежные лампы ГУ-50 с анодным напряжением $800 \ldots 1000 \mathrm{~B}$.

Целевое назначение ультразвукового генератора с магнитострикционным излучателем - это отдельная работа. Сейчас можно с уверенностью говорить, что это не только школьная демонстрационная установка, но и распылитель топлива в тепловых двигателях различного типа [4]. Распылитель позволит увеличить полноту сгорания топлива. Естественно, что распыление топлива потребует дополнительных энергетических затрат. Расчеты показали, что эти затраты во много раз меньше мощности тепловых машин.

Способы увеличения полноты сгорания топлива надо искать в основных физических явлениях, которые начинают изучать в школьном курсе физики, но, к сожалению, не уделяют много внимания их практическому применению.

При изучении звуковых колебаний в школьном курсе физики на уроке была проведена демонстрация опыта распыления капли воды ультразвуком. Автором этого опыта является В.В. Майер из Глазовского педагогического института [1]. Капля воды на конце ферритового стержня практически мгновенно распыляется вверх в виде мельчайших брызг, даже тумана. Сразу появился практический вопрос: зачем надо распылять каплю воды? Надо распылять не воду, а топливо в двигателе внутреннего сгорания, или в турбине, или в прямоточном двигателе и т.д. 
Эта идея тоже не новая, потому что В.В. Майер проводил демонстрации с распылением горючих жидкостей с последующим поджиганием полученного облака [1]. Опыт очень эффектный, но и в нем отсутствует практическое приложение. Этот опыт преследует методическую цель - запоминание действия ультразвука, но не практическую.

Целью работы является изучение возможности практического применения ультразвука для распыления топлива в тепловых двигателях.

С позиции интеллектуальной собственности работа относится к категории «Новое применение известных устройств, способов, материалов».

Новизна работы заключается в применении двойного резонанса при распылении жидкостей для получения нового положительного эффекта - более полного сгорания топлива с целью экономии горючего в различных тепловых двигателях.

Практическая значимость работы — уменьшение расхода топлива тепловыми двигателями, т.е. энергосбережение.

Для достижения поставленной цели был собран транзисторный генератор и магнитострикционный излучатель ультразвука. Такой генератор позволил получить магнитострикционный резонанс ферритового стержня. Однако В.В. Майер работал в основном с открытым пространством. В отличие от его опытов проведено изучение распыления жидкости в замкнутом пространстве. Оказалось, что отражение ультразвуковых волн от стенок значительно усиливает эффект распыления жидкости, этому вопросу уделено основное внимание.

Простейшим опытом более сильного распыления жидкости является помещение магнитострикционного излучателя в стеклянную сферическую колбу. Если диаметр колбы подобрать так, что излучаемый ультразвук в ней будет резонировать, то получится сразу два резонанса. Первый резонанс - это колебания магнитострикционного излучателя в соленоиде, второй резонанс - ультразвуковые колебания воздуха или топливной смеси в замкнутом объеме. Капля жидкости на торце магнитострикционного стержня находится в области двух пучностей двух различных стоячих волн. Одна пучность от стоячей волны в ферритовом стержне магнитострикционного излучателя, вторая пучность от стоячей волны во внутренней среде сферы.

При теоретическом исследовании явления двойного резонанса надо учитывать следующие факты. При переходе волны из одной среды в другую частота и период колебаний не изменяются, но изменяются скорость волны и длина волны. Частота колебаний в ультразвуковой волне одинакова как в феррите стержня, так и в воздухе колбы. Однако скорость звука и длина волны различна в различных средах. Согласование длин волн в феррите и в газе важны для расчета явления двойного резонанса в реальных тепловых двигателях, где рабочим телом является не воздух, а топливная смесь.

Принцип двойного резонанса иллюстрируется схемой на рис. 2. На этом рисунке звуковые волны в стержне и в воздухе изображены схематично, отклонениями давлений среды от нормального давления. Звуковые волны являются продольными, а не поперечными, как показано на схеме. Однако схема поперечных волн более иллюстративна для понимания физического явления. Математический аппарат исследования волн одинаковый как для поперечных волн, так и для продольных.

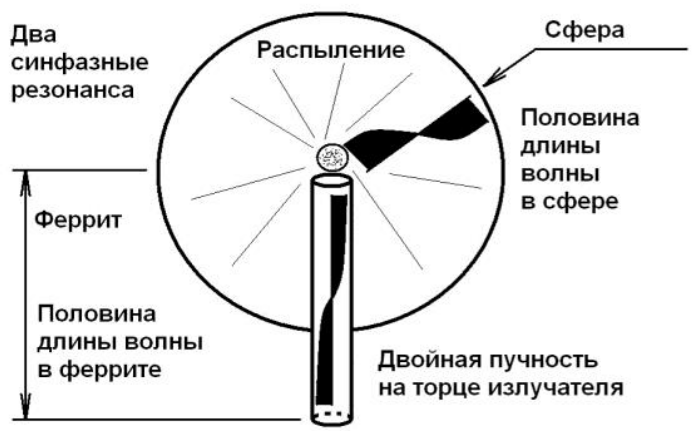

Рис. 2. Принцип распыления топлива двойным резонансом ультразвука 
Совместное одновременное действие указанных двух резонансов в научной литературе не найдено. Задача исследования заключается в определении условий, при которых появляется двойной ультразвуковой резонанс, усиливающий распыление топлива для более полного его сгорания. Экономический и другой полезный эффект, несомненно, имеет место. В этой работе предлагается часть энергии ультразвуковой волны направлять обратно в рабочий объем теплового двигателя для более полного распыления топлива с целью более полного его сгорания. Показано, какие характеристики должен иметь простейшей формы сферический объем и излучатель ультразвука, чтобы наступил двойной резонанс. Для увеличения интенсивности распыления топлива и в излучателе, и в рабочем объеме должно укладываться одновременно целое число полуволн ультразвука.

Ультразвуковой распылитель топлива (УРТ) может устанавливаться на любые типы тепловых двигателей, которые работают на жидком топливе. Он может устанавливаться на входные патрубки двигателей внутреннего сгорания и двухтактных, и четырехтактных. Это может быть и дизель, и реактивный двигатель. Для двигателей внутреннего сгорания предлагается три варианта реализации УРТ:

1) установка УРТ на входной патрубок двигателя сразу после карбюратора или инжектора. Распылитель уменьшает размер капель топлива в горючей смеси, обеспечивает более полное сгорание топлива;

2) установка УРТ на свечу зажигания предотвратит заливание свечи топливом, зажигание горючей смеси в рабочем объеме цилиндра станет более надежным. Свеча зажигания всегда будет сухой;

3) установка УРТ непосредственно в цилиндр двигателя внутреннего сгорания для увеличения распыления топлива перед его сгоранием.

Bblвoдbl. 1. Доказана практически и обоснована теоретически возможность применения ультразвука для распыления топлива в тепловых нагревателях, котлах и двигателях.

2. Предложено новое применение известного способа ультразвукового распыления жидкости для использования в тепловых котлах и двигателях различного типа.

3. Новизна работы заключается в применении двойного резонанса при распылении жидкостей для получения нового положительного эффекта - более полного сгорания топлива с целью экономии расхода горючего в различных тепловых котлах и двигателях.

4. Изготовлен и испытан макет ультразвуковой форсунки, подтверждающий правильность гипотезы о возможности распыления топлива ультразвуком.

5. Практическая значимость работы обоснована экономией энергоресурсов при более полном их сгорании в различных тепловых нагревателях и двигателях.

\section{БИБЛИОГРАФИЧЕСКИЙ СПИСОК}

1. Майер В.В. Простые опыты с ультразвуком. М. : Наука, гл. ред. физ.-мат. лит., 1978.

2. Майер В.В., Вараксина Е.И. Звук и ультразвук в учебных исследованиях. 2-е. изд. Долгопрудный : Интеллект, 2012. 336 с.

3. Коровянская А.Д. Практика накала мощного пентода ГУ-81М // Гагаринские чтения - 39 : сб. тр. конф. / РГТУ-МАТИ им. К.Э. Циолковского. М., 2013. Т. 3. С. 25-27.

4. Коровянская А.Д. Распыление топлива в двигателях двойным резонансом ультразвука // Всероссийский конкурс инновационных проектов и разработок в сфере умной энергетики. Режим доступа: http://gridology.ru/projects/136. Дата обращения: 16.06.2013.

5. Коровянская А.Д., Лебедев В.В. Цифровой блок для ультразвукового магнитострикционного излучателя // Применение инновационных технологий в образовании : материалы XXIV Междунар. конф., Троицк - Москва, 26-27 июня 2013 г. С. 750-751.

\section{REFERENCES}

1. Mayer V.V. Prostye opyty s ul'trazvukom [Simple Experiments with Ultrasound]. Moscow, Nauka Publ., Main editorial office of physical and mathematic literature, 1978.

2. Mayer V.V., Varaksina E.I. Zvuk i ul'trazvuk v uchebnykh issledovaniyakh [Sound and Ultrasound in Educational Investigations]. 2nd edition. Dolgoprudnyy, Intellekt Publ., 2012, 336 p. 
3. Korovyanskaya A.D. Praktika nakala moshchnogo pentoda GU-81M [The Praxis of Heating Powerful Pentode GU-81M]. Gagarinskie chteniya — 39: Sbornik trudov konferentsii [Gagarin Readings - 39: Collection of Works]. Moscow, RGTU-MATI named after K.E. Tsiolkovskiy publ., 2013, vol. 3, pp. 25-27.

4. Korovyanskaya A.D. Raspylenie topliva v dvigatelyakh dvoynym rezonansom ul'trazvuka [Fuel Atomization in Engines by Means of Double Resonance of the Ultrasound]. Vserossiyskiy konkurs innovatsionnykh proektov i razrabotok v sfere umnoy energetiki [All-Russian Tender on Innovational Projects and Developments in the Sphere of Smart Energy]. Available at: http://gridology.ru/projects/136. Date of access: 16.06.2013.

5. Korovyanskaya A.D., Lebedev V.V. Tsifrovoy blok dlya ul'trazvukovogo magnitostriktsionnogo izluchatelya [Digital Unit for Ultrasound Magnetostriction Radiator]. Primenenie innovatsionnykh tekhnologiy v obrazovanii: materialy 24 Mezhdunarodnoy konferentsii Troitsk Moskva, 26-27 iyunya 2013 g. [Using Innovational Technologies in Education: Works of 24th International Conference Troitsk — Moscow, June 26-27]. 2013, pp. 750—751.

Поступила в редакцию в октябре 2013 г.

Об авторах: Коровянская Анастасия Денисовна - ученица, МОУ «Гимназия № 5», 141092, Московская область, г. Юбилейный, ул. Соколова, д. 3; Nasti96@bk.ru;

Лебедев Владимир Валентинович доктор технических наук, профессор кафедры прикладной механики и математики, Мытищинский филиал, ФГБОУ ВПО «Московский государственный строительный университет» (ФГБОУ ВПО «МГСУ»), Московская область, г. Мытищи, Олимпийский проспект, д. 50; Lebedev_v_2010@mail.ru.
About the authors: Korovyanskaya Anastasiya Denisovna - student, municipal general education institution Gymnasium no. 5, 3 Sokolova st., Yubileyniy, Moscow Region, 141092, Russian Federation; Nasti96@bk.ru;

Lebedev Vladimir Valentinovich Doctor of Technical Sciences, Professor, Department of Applied Mechanics and Mathematics, Mytishchi branch, Moscow State University of Civil Engineering (MGSU), 50 Olimpiyskiy Prospect, Mytishchi, Russian Federation; Lebedev_v_2010@mail.ru.

Для цитирования:

Коровянская А.Д., Лебедев В.В. Ультразвуковая форсунка [Электронный ресурс] // Строительство: наука и образование. 2013. Вып. 4. Ст. 3. Режим доступа: http://www.nsojournal.ru.

For citation:

Korovyanskaya A.D., Lebedev V.V. Ul'trazvukovaya forsunka [Acoustic Burner]. Stroitel'stvo: nauka i obrazovanie [Construction: Science and Education]. 2013. no. 4, paper 3. Available at: http://www.nso-journal.ru. 